Corrigendum

\title{
Corrigendum to "New Data on Food Consumption in Pre-Hispanic Populations from Northwest Argentina (ca. 1000-1550 A.D.): The Contribution of Carbon and Nitrogen Isotopic Composition of Human Bones"
}

\author{
María Soledad Gheggi and Verónica Isabel Williams \\ CONICET-Instituto de Arqueología, Facultad de Filosofía y Letras, Universidad de Buenos Aires, 25 de Mayo 217, 3rd floor, \\ C1002ABD Buenos Aires, Argentina
}

Correspondence should be addressed to María Soledad Gheggi; solelingheggi@yahoo.com.ar

Received 22 June 2015; Accepted 2 August 2015

Copyright (C) 2015 M. S. Gheggi and V. I. Williams. This is an open access article distributed under the Creative Commons Attribution License, which permits unrestricted use, distribution, and reproduction in any medium, provided the original work is properly cited.

The map published under Figure 1 in the paper entitled "New Data on Food Consumption in Pre-Hispanic Populations from Northwest Argentina (ca. 1000-1550 A.D.): The Contribution of Carbon and Nitrogen Isotopic Composition of Human Bones" [1] was modified from a map originally designed and published by María Cristina Scattolin in the following paper: "Categoremas Indígenas y Designaciones Arqueológicas en el Noroeste Argentino Prehispánico," Chungará, Revista de Antropología Chilena, 2006, 38 (2): $185-196$, thus having a previous copyright. The figure and its corrective legend are presented here.

\section{References}

[1] M. S. Gheggi and V. I. Williams, "New data on food consumption in pre-hispanic populations from Northwest Argentina (ca. 1000-1550 A.D.): the contribution of carbon and nitrogen isotopic composition of human bones," Journal of Anthropology, vol. 2013, Article ID 258190, 13 pages, 2013.

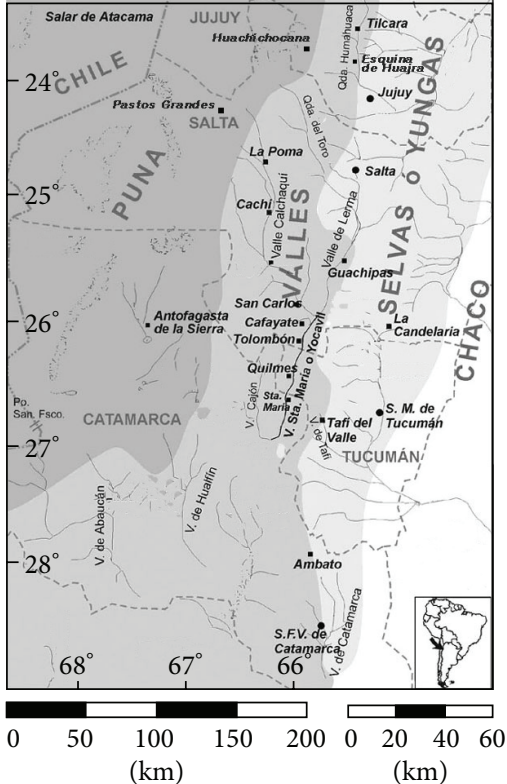

Figure 1: Northwest Argentina: main geographical areas and archaeological sites mentioned in the text. Sites comprised in this study are marked with a star symbol. Modified from Scattolin (2006). 

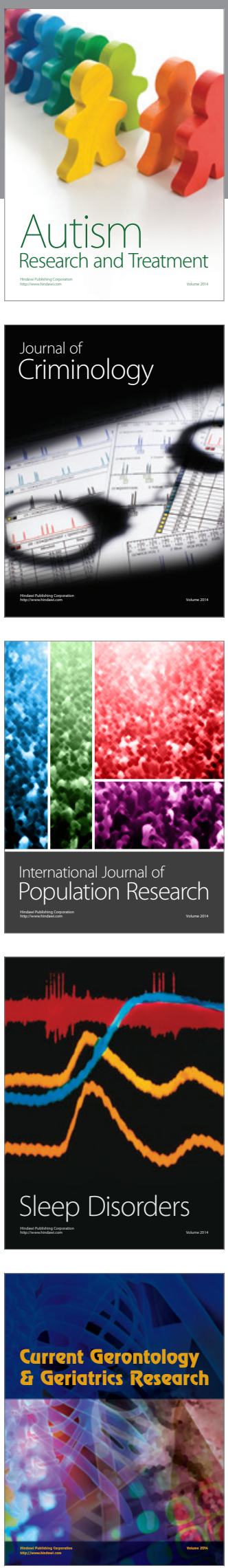
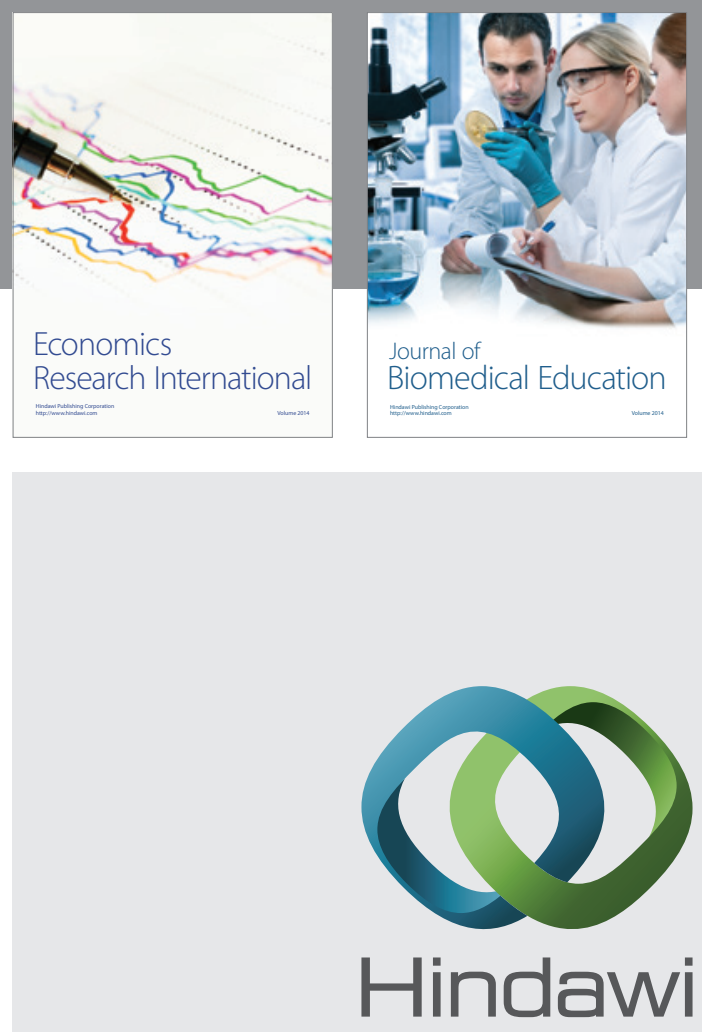

Submit your manuscripts at

http://www.hindawi.com
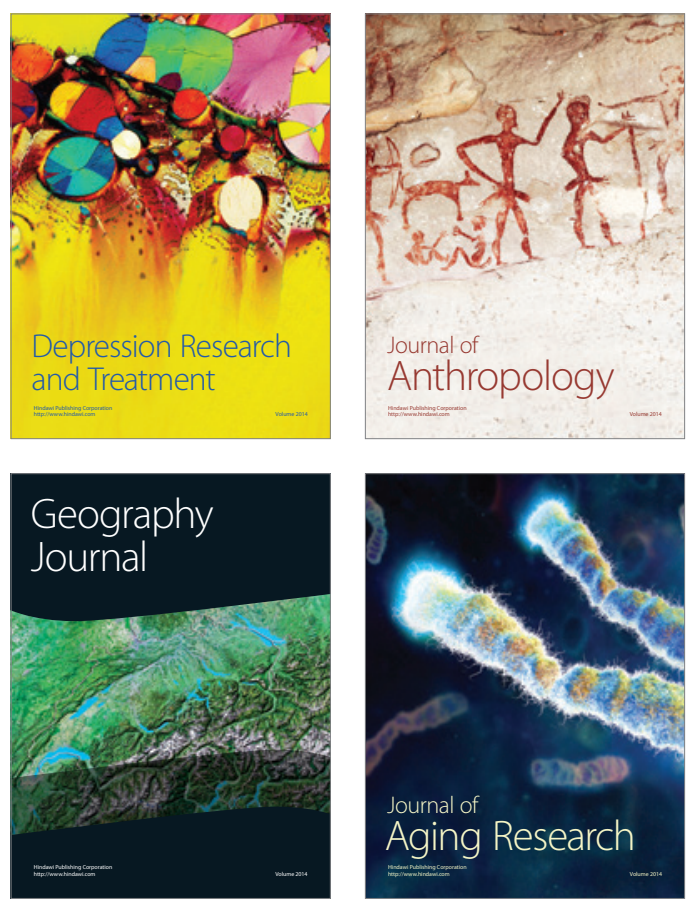
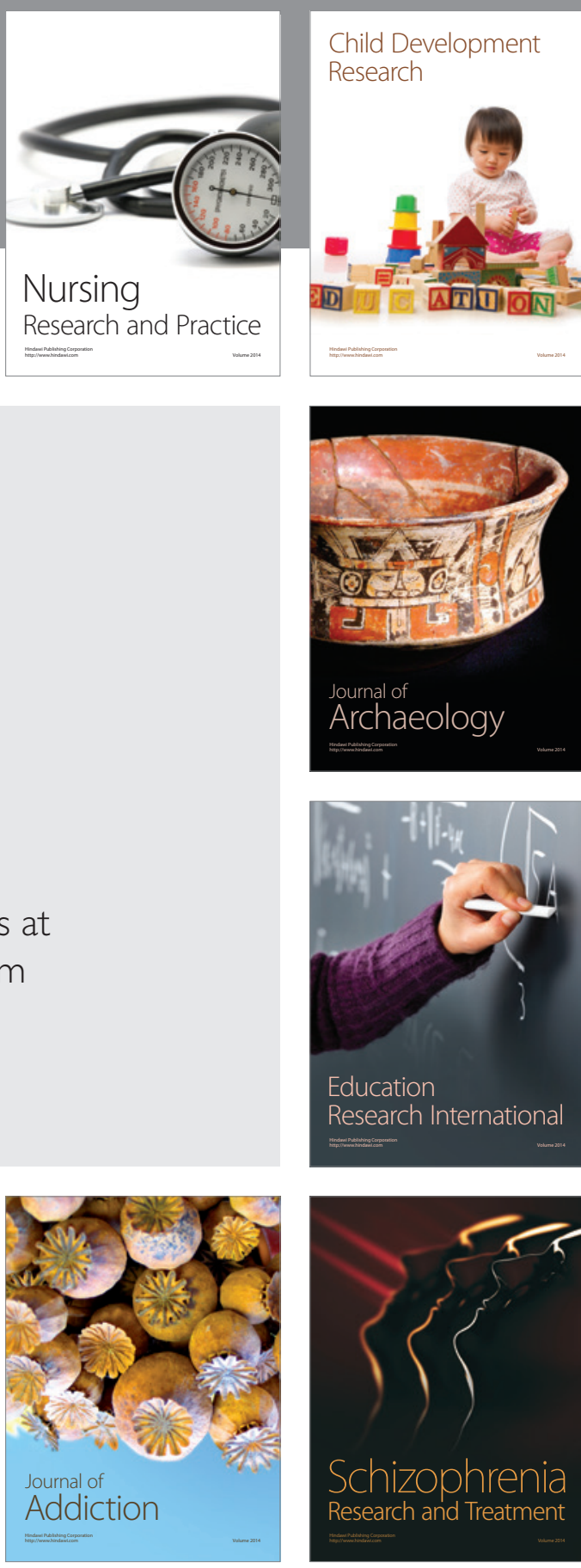

(D)
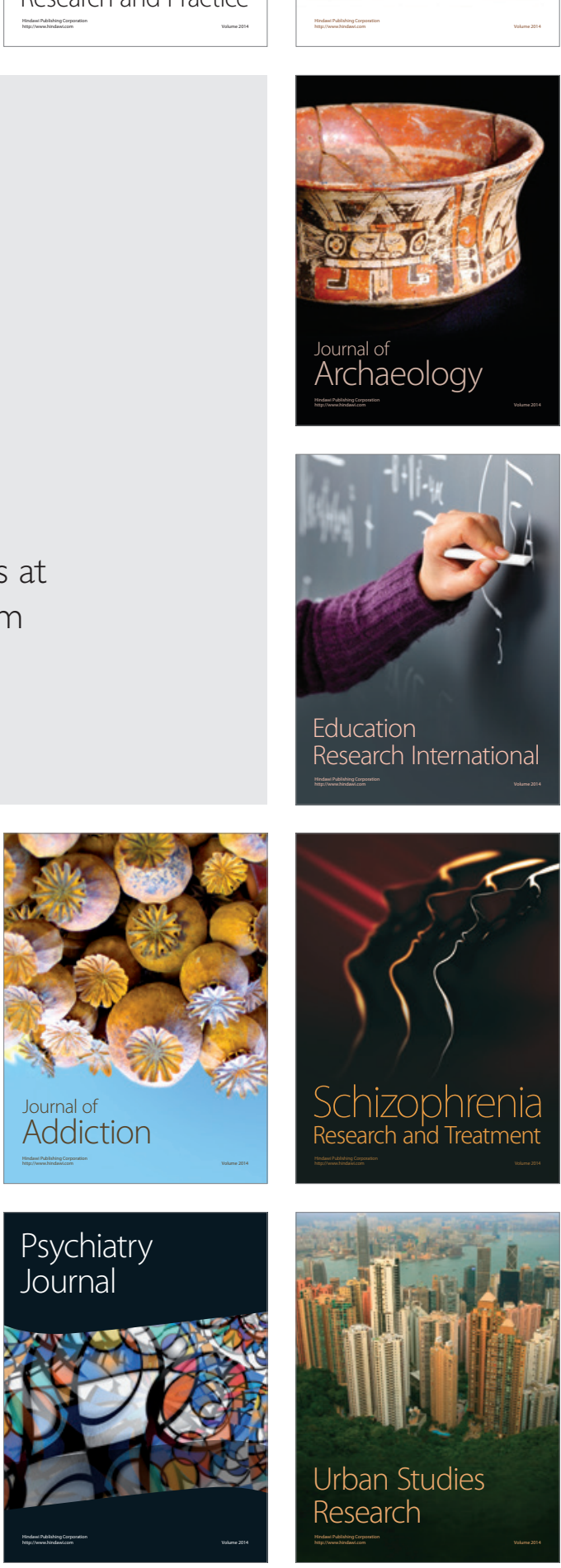